\title{
Multi-engagement, Learning Approach and Student Learning Outcomes: Evidence from Taiwanese Private University
}

\author{
Michael Yao-Ping Peng ${ }^{1}$, Rong-Sheng Wang ${ }^{2}$, Feng-Chi Liu ${ }^{3}$, Sheng-Hwa Tuan ${ }^{4, *}$ \\ ${ }^{1}$ Department of Business Administration, Hsuan-Chuang University, Taiwan \\ ${ }^{2}$ Department of Law, Hsuan Chuang University, Taiwan \\ ${ }^{3}$ Department of Information Management, Hsuan Chuang University, Taiwan \\ ${ }^{4}$ Institutional Research Center, Hsuan Chuang University, Taiwan
}

Copyright $\subset 2017$ by authors, all rights reserved. Authors agree that this article remains permanently open access under the terms of the Creative Commons Attribution License 4.0 International License

\begin{abstract}
Higher education plays a key role in national economic development. According to statistics from the Ministry of Education (MOE), there were 166 higher education institutions (HEIs) in Taiwan in 2014. This form of mass education provides more educational opportunities for students, but also causes problems like low teaching quality and competitiveness which decrease students' learning outcomes. Using multilevel models, this study examined the strength of the association between student engagement and the development of student learning outcome based on data from 1,226 students. This study examined how learning and institutional scales contribute to the narrative on academic rigor at a medium, private teaching institution. The results indicate that a specific type of engagement is linked to a particular learning outcome, which means that not every engagement type has an equal impact thereon.
\end{abstract}

Keywords Institutional Research, Institutional Engagement, Student Engagement, Student Learning Outcome

\section{Introduction}

Amid the knowledge-based economy, the core value and study pattern of establishing competitive advantages for students have already been changed. Knowledge has become the dispensable components of developing students' key skills and core capabilities $[10,36]$, while such higher education topics as the learning outcomes and research on educational administration have also drawn much attention from universities and colleges [7, 10, 29]. Previous literatures indicate that concentration and study pattern serve as the driving forces of stimulating and creating students' core abilities with the positive influences on study efficiency; however, educational administration advocates that the efficient study resources and environment from the executives [12], which are conducive to the improvement of study efficiency, are the sources of valuable assets and competitive advantages for students to grow up $[12,28]$. The perspective of institutional engagement differs from the student engagement on examining students' knowledge learning and ability cultivation, so it should be attached great importance to and we should establish efficient study activities and approaches through sound transforming systems so as to improve study abilities and learning outcomes.

HEIs in Taiwan can be divided into two kinds, i.e. public and private institutions. In the case of rich subsidies and sound study situation, the qualities of students in public universities are better than that of students in private universities, and the condition of study and economy for most of students in private universities are still poorer than those in public. Thus, with several unfavorable influences, the exploration of study input and learning outcomes of students in private universities is an interesting topic under the research situation of private universities in Taiwan.

Researchers on learning believe that students can carry out study driven by learning stimulus, so as to acquire the ability of developing new knowledge and further improve the learning outcomes [7, 39]. Most of the definitions concerning student learning are discussed from the learning process or/and outcomes, and those researchers propose that students can effectively deal with course knowledge in the learning process $[12,20,28,29]$, which can not only be conducive to adsorbing knowledge for students but also improve the learning ability and outcomes through self-learning. There are a lot of scholars have done research on the way of students' improving learning input to acquire knowledge through learning activities and creating learning 
stimulus with student learning theory $[7,8,10,28,29]$, and help students, under the uncertain and competitive knowledge-based economy, to gain the favorable position in the future job market by continuous learning, improvement, accommodation and lifting the ability to address the changes in environment [5]. The conclusion is that there should be certain connections towards learning input with ability and approaches, and when putting it into the discussion of connections between institutional engagement and learning outcomes within educational administration, it is necessary to include the influence of learning input to outcomes through learning approaches and abilities with a more comprehensive model.

With references to the previous researches, in this paper, the learning process was divided into learning approaches and abilities, which both are the ways and abilities applied in the learning process, and finally introduce the measurable learning outcomes that can change with the fluctuation of input and be more dynamic compared with learning approaches and ability. There are lots of literatures supporting that students can transform accumulated knowledge through learning process and improve learning ability $[7,8,41]$, so the contribution of various learning approaches towards learning abilities should not be ignored. But with the limited resources and time, it is difficult for students to simultaneously attach the same significance to all learning approaches, or make the same efforts, so it is of necessity to clarify the appropriate and more important learning approaches, inject more time and efforts into them and focus on strengthening administration so as to effectively improve the learning ability $[7,20]$. Therefore, in the context of research on the educational administration, how to enhance learning approaches and abilities from the perspectives of institutional engagement and student engagement has become the important topic to help the weak students to gain the efficient learning outcomes [19, 28]. This study aims to explore the relationship among institutional engagement, student engagement, learning approaches, leaning ability and learning outcomes, taking the students from domestic private universities as the samples, and further do research on the influence of learning approaches on student's learning abilities.

This paper has made contribution to research in two ways. First, on the basis of proven information and documents, it explores the influence of institutional engagement and student engagement towards the learning outcomes for weak students through learning approaches and abilities, and proves that the intermediary results of learning approaches and abilities differ from the influence of administration on learning outcomes narrated in a concept way by most of previous literatures. Second, the previous literature emphases that student learning should be divided into process (learning approaches) and result (learning ability), so in response to this theory, it further specifies student learning into leaning approaches and ability so as to explore the relationship between learning approaches and important administration and student engagements. The framework of this study is as follows:

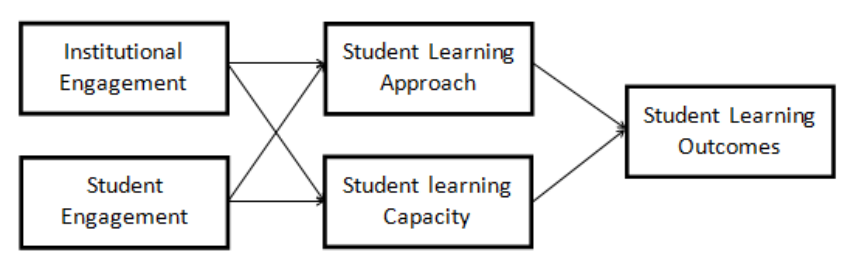

Figure 1. Research framework

\section{Literature Review}

\subsection{Institutional Engagement}

Concurrent with the rising interest in student engagement, resource management and the effective use of financial resources which called institutional engagement represented another broad area of concern for policymakers, the public, and college administrators. Regional accrediting agencies (see Higher Learning Commission, 2004) also are focused on more than institutional stability and financial security as a basis for institutional accreditation. They are asking institutions to provide evidence for student learning and success in fulfilling respective institutional missions. Institutional decisions regarding the allocation of financial resources, various regulatory requirements, and established norms of institutional administration - all of which can contribute to higher administrative spending - may contribute to lower levels of student engagement. Weerts [40] also suggested that an engagement model of institutional advancement would generate public and private support for public higher education, and more broadly benefit student. Thus, more institutional engagement would facilitate college students perform better and design effective policies and programs to enhance student learning outcomes and help students succeed. This study thus proposes the following hypotheses:

H1: Institutional engagement positively correlates with student learning approach.

H2: Institutional engagement positively correlates with student learning capacity

\subsection{Student Engagement}

In the past decades, scholars has established newer and richer understanding and narrations in the study of learning science on the basis of numerous known knowledge [20], especially through the research on the observation of others' behaviors, and scholars began to try a needed knowledge base of developing and completing a certain task [26]. Those knowledge learning activities can be carried out by the influences of supervisor and immediate relatives, knowledge of learning approaches and theme, and practical knowledge acquired from the class [29]. What is more 
important is that those learning approaches and beliefs have already rooted in the mind of students before they are taught by teachers in the class $[35,39]$. In the primary stage, students just like apprentices observing teachers' behaviors, and they never do a systematic study and imitation, instead they would provide a set of acceptable behavior scripts through the memory of the plots [19]. Therefore, the fundamental purpose of developing student learning is to improve student engagement to the learning activity applying all learning potential, not the traditional teaching approaches. Student engagement can be regarded as the quality of learning experience, so the quantity of physiological and psychological energy in the learning depends on the role that student play in the learning but not the passive body influenced by the environment $[8,28]$. As far as psychology is concerned, learning input includes energy, involvement, professional efficacy and another important component that is absorption [34]; specifically speaking, according to the definition of Schaufeli and Salanova [33], students can complete the learning task with high-level energy and mental resilience, as well as the willing and persistence of input effort, even in the tough context; they would intensively carry out leaning, and realize its contributions such as significance, enthusiasm, inspiration and challenge; and completely concentrate on his own learning task in a pleasant way. This study thus proposes the following hypotheses:

H3: Student engagement positively correlates with student learning approach

H4: Student engagement positively correlates with student learning capacity

\subsection{Student Learning Approach}

The study indicates that the learning approaches can be influenced by teachers, families, attribute of subject topic and the acquisition of practical knowledge in the class [29]. Therefore, the purpose of stimulating students to learn is to improve the participation level in learning activities, so as to help them to release potential abilities but not being taught by traditional teaching method; so in the process of enlightening students to learn, teachers should transform the existing teaching method of teacher's guidance and passive learning into the student-core and active learning, so as to guide students to explore the in-depth knowledge connotation and apply the acquired knowledge to the different conditions [21,37]. In the past, scholars have proposed different narrations and descriptions in accordance with the connotation and classification of students' approaches to learning $[11,23]$. The learning approaches can create the high-quality university teaching practices $[4,32,37]$, which are developed by the collaboration among students, colleges, universities and teachers, so as to nurture in-depth and concrete teaching models, including stimulating positive student's response, establishing background knowledge and impart the broader interlink among different ideas. Scholars agree that effective learning approaches and strategies are certain commitments of understanding textbooks and information from the student personally, which reflect the application of different learning strategies, such as extensive reading, integration of resources, collaborated discussion of ideas, devotion to connecting single piece of information with broad concepts and models, and application of knowledge in the real world $[3,32,37]$. Thus, this study proposes the following hypothesis:

H5: Student learning approach positively correlates with student learning outcome

\subsection{Student Learning Capacity}

Therefore, the approach of learning input means the establishment of generic student competencies (GSCs), such as problem-solving, communication, and interpersonal connection, which play an important role in the learning process [10]. In the higher education, the core ability differs from the soft and hard strengths with multi levels, and in the study of exploring leaning ability and basic ability, it is difficult to find the concrete nature and prominent differences of job-hunting power because of the different classification standards [1]. Based on this, Hennemann and Liefner [16] concluded a comprehensive frame of influence factors towards the cultivation of job-hunting power for graduates in the universities, so as to explain the important role that capacity and capability play in this process. Hennemann and Liefner [16] made the distinction among capacity, capability and competence, and defined capacity as the appropriate confidence that individuals deal with matters in the uncertain environment and could continuously learn something from experiences; capability has the nature of future-orientation, so it can be regarded as the basic results in the interactive learning; competence means the learner possesses the adequate confidence to demonstrate capability in the broad and diverse context and continuously improve the application of capability $[6,15]$. Nygaard et al. believe that in university education, student learning should include knowledge, skills and competence, of which learning capacity contains personal quality and social background [18] and applies knowledge and skills through reflection. This study thus proposes the following hypothesis:

H6: Student learning capacity positively correlates with student learning outcome

\subsection{Student Learning Outcome}

Learning outcomes serve as an indicator to evaluate the students' learning results. The purpose of measuring learning outcomes is to help students to get understanding of his own learning conditions and make them the evidence for teachers and students to improve teaching quality and learning efficacy [13]. The study indicates that learning is a 
process of creating and evolving behavior driven by activities and experiences; so students can recognize the influence of learning communication by class participation and interaction with teachers and peers, and his performance under certain measurement indicator after learning [28,29]. Although scholars take the same measurement method towards learning outcomes, Pike, Smart, Kuh, \& Hayek [30] remind that most of previous studies examine the learning performance in the different time points, such as freshman, sophomore, junior and senior students, and the single analysis of these students may cause errors to study result, that is there are differences of learning outcomes from different grades because of relationship among variables. Therefore, in order to satisfy this topic, this study will control the grade of the testees to reduce the difference of variables among samples. This study, referring to the result from Campbell and Cabrera [7], takes students' scores as the variables to measure learning outcomes and explores the influence of learning approaches and capabilities towards academic records.

\section{Methodology}

\subsection{Sampling}

To measure the large-scale data on the effectiveness of learning about private school college students input, learning methods, learning ability, this study collected the samples of a private university students in Taiwan and integrated data from the school library for analysis. This study selected 2014 Students' Research Database Questionnaire from a private school in Taiwan to be Object of study, the search database quarter 1203 recorded document data, after deduction of incomplete information, retain valid samples units 1003 , for an effective response rate of $83.4 \%$. Since freshmen were not familiar with the learning environment, all participants in this study were sophomores, juniors and seniors. $51.8 \%$ of them were female respondents. $48.2 \%$ of them were sophomores, $31.3 \%$ juniors and $20.5 \%$ seniors. Moreover, most participants $(65.0 \%)$ spent less than five hours on self-study each week, and $23.3 \%$ of them 6-10 hours. In order to generalize the results, this study simplified the influence of disciplines, with $75 \%$ of the participants being social science majors and $25 \%$ natural science majors.

\subsection{Measurement}

\subsubsection{Institutional Engagement}

This study takes the factor score that includes 21 questions such as "the performance of learning mainly depend on the learning environment", "the performance of learning mainly depend on the teaching methods" in the data bank, with "strongly disagree", "disagree", "normal", "agree", and "strongly agree" by Likert five degrees, encoding $1,2,3,4,5$, in which the higher total score means the higher level of institutional engagement. We take varimax of orthogonal rotation to extract factors by method of principal axis, so as to extract three factors from analysis results of the exploratory elements, the variables of explaining can reach $57.27 \%$, and the load capacity of various factors is between $0.48-0.83$, and the whole Cronbach's $\alpha$ value is 0.87 . The names of variables are determined in accordance with 4 factors, which are "learning environment", "learning support", "soft and hard equipment demand" and "interaction between teachers and students", so we will further analyze these four dimensions. The second order CFA shows GFI $=0.98, \mathrm{AGFI}=0.99$ and RMSEA $=0.02$, and other indicators such as NFI, CFI, RFI and IFI are $0.96,0.98,0.92$, and 0.98 respectively.

\subsubsection{Student Engagement}

This study takes the factor score that "I am concentrated on the learning activities in the class (such as practicing operation, discussion, etc.), which includes 4 questions of "role identity", 4 of "learning identity", and 2 of "goal-oriented learning", and 3 of "career planning". Extracting three factors from analysis results of the exploratory elements, the variables of explaining can reach $65.71 \%$, and the load capacity of various factors is between $0.46-0.76$, and the whole Cronbach's $\alpha$ value is 0.86 . The second order CFA shows GFI $=0.98$, AGFI $=0.99$ and RMSEA $=0.04$, and other indicators such as NFI, CFI, RFI and IFI are 0.92 .

\subsubsection{Student's Learning Approaches}

This study takes the factor score that "I often have access to the information concerning my future development", which belongs to the attitude towards university in the questionnaire, and they are divided into 5 questions of "self-reflection learning", 5 of "problem-oriented learning", and 3 of "active learning". Extracting three factors from analysis results of the exploratory elements, the variables of explaining can reach $51.32 \%$, and the load capacity of various factors is between $0.45-0.80$, and the whole Cronbach's $\alpha$ value is 0.78 . The second order CFA shows $\mathrm{GFI}=0.98$, AGFI $=0.99$ and RMSEA $=0.04$, and other indicators such as NFI, CFI, RFI and IFI are 0.92.

\subsubsection{Student Learning Capacity}

Student's learning capacity includes the factor score that "the performance of student's learning mainly depends on his own devotion" with 4 question items. Extracting three factors from analysis results of the exploratory elements, the variables of explaining can reach $49.77 \%$, and the load capacity of various factors is between $0.54-0.80$, and the whole Cronbach's $\alpha$ value is 0.66 . The second order CFA shows $\mathrm{GFI}=0.98, \mathrm{AGFI}=0.99$ and $\mathrm{RMSEA}=0.04$, and other indicators such as NFI, CFI, RFI and IFI are 0.92 . 


\subsubsection{Student Learning Outcomes}

This study, using the result of Campbell and Cabrera [7], shows that the learning outcomes mainly depend on the scores of student in campus, so it takes the score as the symbol of his learning outcomes, and explores the influence of learning approach and learning capacity toward his scores in the university.

\section{Analysis Results}

\subsection{Reliability and Viability}

This study developed a parameters model frame of job-hunting power for students after the above literatures and testing of validity and reliability, and then made use of LISREL to study the efficiency of actual measure model and comprehensive appropriate degree of evaluation study model, and examined the assumption proposed by this study. We can use Maximum Likelihood to estimate the model.

Before the evaluation and testifying of the fit measure for theory assumption model, we should carry out correlation test among various indicators as shown in Table 2, and its result indicates that the all correlation coefficients is above the .05 prominent level, that means there is certain correlation among 13 indicators and absolute values among them are not close to 1 .

The fit measure of comprehensive model serves to evaluate the fit degree of the whole model and observation information, so as to examine the outside quality of this model. According to scholars [31], comprehensive fit measure evaluation includes absolute, value-added and concise fit measures. In the absolute fit measure, RMSEA $=.043$, belonging to a good fit measure standard of less than .05 , and at the same time, GFI $=.972$ and $\mathrm{AGFI}=.954$, which are over .90 . So we can conclude that the fit measure degree among this theory model and collected sample documents is pretty sound. In the value-added fit measure, $\mathrm{NFI}=.961, \mathrm{CFI}=.974, \mathrm{IFI}=.974$ and $\mathrm{RFI}=.942$, which are above .90 . And in the concise fit measure, $\mathrm{PNFI}=.646$ and $\mathrm{PGFI}=.579$, which are above .50 , and $\mathrm{AIC}=338.746$ is less 5858.59 than independent model, so this conclusion meet the standard that AIC of theory model must less than that of independent model, demonstrating the simplifying variables of this model can effectively reflect the relationship among various variables. As above shows, the fit measure of this study model and comprehensive model of observation information reach the ideal standard and serve as the concise model.

Table 1. Descriptive analysis

\begin{tabular}{|c|c|c|}
\hline \multicolumn{1}{|c|}{ Variables } & Mean & SD \\
\hline Institutional engagement & & \\
\hline Learning environment (LE) & 3.45 & 0.80 \\
\hline Learning support (LS) & 3.40 & 0.66 \\
\hline $\begin{array}{l}\text { Soft and hard equipment demand } \\
\text { (SHED) }\end{array}$ & 3.32 & 0.74 \\
\hline $\begin{array}{l}\text { Interaction between teachers and } \\
\text { students (ITS) }\end{array}$ & 3.42 & 0.77 \\
\hline Student engagement & & \\
\hline Role identity (RI) & 3.64 & 0.76 \\
\hline Learning identity (LI) & 3.65 & 0.73 \\
\hline Goal-oriented learning (GOL) & 3.42 & 0.85 \\
\hline Career planning (CP) & 3.73 & 0.83 \\
\hline Student learning approach & & \\
\hline Self-Reflection learning (SRL) & 3.34 & 0.66 \\
\hline Problem-Based learning (PBL) & 3.17 & 0.81 \\
\hline experiential learning (EL) & 2.98 & 0.81 \\
\hline Student learning capacity (SLC) & 3.67 & 0.76 \\
\hline Student learning outcomes (SLO) & 74.69 & 13.51 \\
\hline
\end{tabular}

Table 2. Measurement

\begin{tabular}{|c|c|c|c|c|c|c|c|c|c|c|c|c|c|}
\hline & 1 & 2 & 3 & 4 & 5 & 6 & 7 & 8 & 9 & 10 & 11 & 12 & 13 \\
\hline LE & 1 & $.269^{* *}$ & $.179^{* *}$ & $.223^{* *}$ & $.314^{* *}$ & $.277^{* *}$ & $.198^{* *}$ & $.425^{* *}$ & $.268^{* *}$ & $.316^{* *}$ & $.179^{* *}$ & $.532^{* *}$ & $.100^{* *}$ \\
\hline LS & $.269^{* *}$ & 1 & $.664^{* *}$ & $.524^{* *}$ & $.533^{* *}$ & $.436^{* *}$ & $.400^{* *}$ & $.357^{* *}$ & $.502^{* *}$ & $.343^{* *}$ & $.325^{* *}$ & $.420^{* *}$ & $.138^{* *}$ \\
\hline SHED & $.179^{* *}$ & $.664^{* *}$ & 1 & $.414^{* *}$ & $.419^{* *}$ & $.341^{* *}$ & $.353^{* *}$ & $.238^{* *}$ & $.409^{* *}$ & $.290^{* *}$ & $.264^{* *}$ & $.291^{* *}$ & $.134^{* *}$ \\
\hline ITS & $.223^{* *}$ & $.524^{* *}$ & $.414^{* *}$ & 1 & $.460^{* *}$ & $.334^{* *}$ & $.379^{* *}$ & $.265^{* *}$ & $.454^{* *}$ & $.247^{* *}$ & $.442^{* *}$ & $.302^{* *}$ & $.087^{* *}$ \\
\hline RI & $.314^{* *}$ & $.533^{* *}$ & $.419^{* *}$ & $.460^{* *}$ & 1 & $.534^{* *}$ & $.471^{* *}$ & $.451^{* *}$ & $.509^{* *}$ & $.386^{* *}$ & $.379^{* *}$ & $.417^{* *}$ & $.248^{* *}$ \\
\hline LI & $.277^{* *}$ & $.436^{* *}$ & $.341^{* *}$ & $.334^{* *}$ & $.534^{* *}$ & 1 & $.531^{* *}$ & $.434^{* *}$ & $.554^{* *}$ & $.281^{* *}$ & $.277^{* *}$ & $.405^{* *}$ & $.090^{* *}$ \\
\hline GOL & $.198^{* *}$ & $.400^{* *}$ & $.353^{* *}$ & $.379^{* *}$ & $.471^{* *}$ & $.531^{* *}$ & 1 & $.421^{* *}$ & $.654^{* *}$ & $.259^{* *}$ & $.302^{* *}$ & $.268^{* *}$ & $.065^{*}$ \\
\hline $\mathrm{CP}$ & $.425^{* *}$ & $.357^{* *}$ & $.238^{* *}$ & $.265^{* *}$ & $.451^{* *}$ & $.434^{* *}$ & $.421^{* *}$ & 1 & $.429^{* *}$ & $.296^{* *}$ & $.240^{* *}$ & $.546^{* *}$ & $.170^{* *}$ \\
\hline SRL & $.268^{* *}$ & $.502^{* *}$ & $.409^{* *}$ & $.454^{* *}$ & $.509^{* *}$ & $.554^{* *}$ & $.654^{* *}$ & $.429^{* *}$ & 1 & $.368^{* *}$ & $.394^{* *}$ & $.339^{* *}$ & .037 \\
\hline POL & $.316^{* *}$ & $.343^{* *}$ & $.290^{* *}$ & $.247^{* *}$ & $.386^{* *}$ & $.281^{* *}$ & $.259^{* *}$ & $.296^{* *}$ & $.368^{* *}$ & 1 & $.255^{* *}$ & $.361^{* *}$ & $.150^{* *}$ \\
\hline $\mathrm{AL}$ & $.179^{* *}$ & $.325^{* *}$ & $.264^{* *}$ & $.442^{* *}$ & $.379^{* *}$ & $.277^{* *}$ & $.302^{* *}$ & $.240^{* *}$ & $.394^{* *}$ & $.255^{* *}$ & 1 & $.222^{* *}$ & $.079^{*}$ \\
\hline SLC & $.532^{* *}$ & $.420^{* *}$ & $.291^{* *}$ & $.302^{* *}$ & $.417^{* *}$ & $.405^{* *}$ & $.268^{* *}$ & $.546^{* *}$ & $.339^{* *}$ & $.361^{* *}$ & $.222^{* *}$ & 1 & $.165^{* *}$ \\
\hline SLO & $.100^{* *}$ & $.138^{* *}$ & $.134^{* *}$ & $.087^{* *}$ & $.248^{* *}$ & $.090^{* *}$ & $.065^{*}$ & $.170^{* *}$ & .037 & $.150^{* *}$ & $.079^{*}$ & $.165^{* *}$ & 1 \\
\hline
\end{tabular}




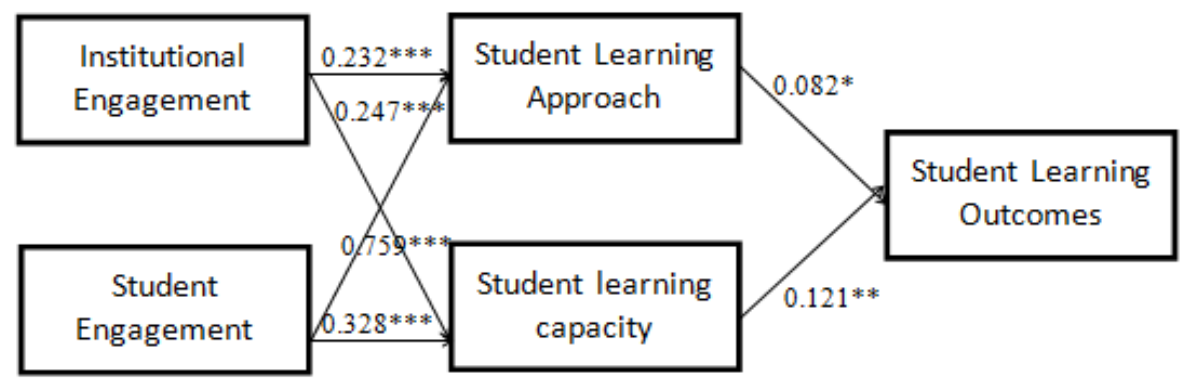

Figure 2. Path analysis

\subsection{SEM Analysis Results}

This study employed PLS to evaluate relationships between multi variables under the comprehensive model. If the relationship between input and approach, and capacity and outcomes can be obtained, it will contribute to helping universities and teachers to improve course design and teaching method, so as to enhance the students' learning performance. This study used SEM to make an analysis with effective 1003 student samples. Apart from improving the stability and fit measure of this model, it also adds the generalized degree of this study. As the fig. 2 shows, the conclusion from the SEM path indicates that the coefficient of standardization of institutional engagement towards student learning approaches and learning capacity reaches statistic prominence $(\beta=.232, p<.001 ; \beta=.247, p<.001)$, which supports $\mathrm{H} 1$ and $\mathrm{H} 2$. And that of student engagement also reaches that level $(\beta=.759, \mathrm{p}<.001 ; \beta=.328, \mathrm{p}<.001)$, which supports $\mathrm{H} 3$ and $\mathrm{H} 4$. In addition, the coefficient of standardization of learning approaches $(\beta=.082, p<.05)$ and learning capacity $(\beta=.121, \quad p<.01)$ towards learning outcomes also reaches statistic prominence, which supports H5 and H6. So we can conclude that the improvement of learning approaches and learning capacity are conducive to the promotion of learning outcomes.

\section{Conclusions}

\subsection{Research Findings}

This study is based on a study sample of a private university in Taiwan, using the mode of input-enhancement-output to test the relevance of school investment, students investment, learning approaches, learning ability and learning effectiveness, integrate the variables available from the data of database, then put forward practical recommendations on student learning through validation studies architecture. Based on the results, these following studies have found.

Under the validation sample of private college students, the results about the path relationship of the study model showed that school investment has positive significant effects in learning approaches and learning ability, and that when school increase students' devotions in learning resources will enable students' understandings and recognitions of the role and obligations of being a student. It will help to increase participation in the learning activities, thereby enhancing its ability to learn later. Furthermore, the extent of the student's own input, can also improve learning approaches and learning ability, the results match with the concept of achievement motive proposed by Chen etc. And that is the expectations and social values within the group members will have different impacts on students' construction of achievement goals, and further derive important meanings and results to their learning investment. In other words, due to students' family background, they suffered a higher degree of social expectations from parents or family and roles of obligations, it is easy to be aware of their own role and have more strong feelings to participate in various learning activities and put inputs. In addition, the path coefficients showed that the improvements of students' devotion in learning approaches and learning ability are greater than the investment in school, meaning that apart from the school investment in resources from to improve students' learning environment and learning resources, the encouragement of students' psychological plane should also be taken seriously. Same as Petersen and the others' research, stressed important personal internal factors like students use self-determination to guide motivation or self-esteem and perceived stress, will help them to engage in academic learning and other related acts, the conclusion can also be considered as substitution within the University of extrinsic reward in the motivational factors reorientation.

Furthermore, this study wants to discuss the relationship between students' learning approaches, inter-learning ability and learning effectiveness, and understanding in the use of learning approaches, and what ways can help to improve learning outcomes of the undergraduates. The description will be divided into two parts according to variables: First, reflections of learning, learning problem solving, and active learning all have a positive impact on learning outcomes. It means that during the process of knowledge acquiring, three learning styles play an important role along with a kind of feedback control mechanism, constantly correcting errors in the process, and 
through conscious or unconscious learning to update the student's individual memory, promote the use of reflections of learning, learning problem solving and active learning, so that students can enhance their learning effects through many skills like the understanding of professional knowledge, theory deduction, principle study of students, the concept of time or stress management. Second, college students are all able to continually participate in learning activities, in addition to absorb new knowledge, at the establishment of affective development, moral education and values, teachers are not only have the responsibilities to teach students academic knowledge, but also teach positive attitudes, social application of soft power and the development of moral qualities when they facing interaction of extracurricular things and people, thereby improving the effectiveness of their learning.

\subsection{Implications}

This study investigates College Students learning process through school investment and students investment in the resources level. Although motivation is an important factor in learning, to enhance students' self-identity and self-efficacy also is a direction that school should strive further, but these two psychological factors were only the sufficient condition to motivate students, not the necessary condition. It recommends that universities can use external assistance and economic support as a basis, that is to say a variety of learning-induced psychological motive can be established in various economic conditions support; If school can provide a stable school campus work-study internship opportunities or promote school environment, such as internships shops, administrative work-study, students can earn in addition to cost of living, but they can also be left in school, studying subjects related practices or participate in service learning experience, so that they feel the fun of learning applications and professional knowledge and ability, and also prevent the problems of ignorance their studies and follow-up investment or other learning problems due to workplace safety or overtime work.

\subsection{Research Limitations and Future Research Direction}

Except for increasing the knowledge absorption, teachers can recommend to strengthen students' ability to use cost-effective ways to solve problems, to reduce the failure possibility of problem solving, the risk of decision-making, and this should guide students to have better learning. For example, a university to promote volunteering and internship trainee program is the key to let student learning outcomes into the rising orbit, the learning activities of students during the school may help to enhance the professional knowledge and ability, but with the learning environment on the school campus is more stable than the outside, its perception of attitudes, values and interpersonal failure to have a clear growth. Therefore, this study suggested that higher education institutions will help students understand their responsibility and social adaptability from learning experience or problem solving through service-learning industry internship or external socialization process.

\section{REFERENCES}

[1] Asif, M., \& Searcy, C. (2014). Determining the key capabilities required for performance excellence in higher education. Total Quality Management \& Business Excellence, 25(1-2), 22-35.

[2] Astin, A. W. (1993). What matters in college?: Four critical years revisited (Vol. 1): Jossey-Bass San Francisco.

[3] Biggs, J. (2003). Aligning teaching and assessing to course objectives. Teaching and Learning in Higher Education: New Trends and Innovations, 2, 13-17.

[4] Biggs, J., \& Tang, C. S.-k. (2011). Society for Research into Higher Education. Teaching for quality learning at university.

[5] Bowman, N. A., \& Park, J. J. (2015). Not all diversity interactions are created equal: Cross-racial interaction, close interracial friendship, and college student outcomes. Research in Higher Education, 56(6), 601-621.

[6] Brown, R., \& McCartney, S. (2004). The development of capability: the content of potential and the potential of content. Education+ Training, 46(1), 7-10.

[7] Campbell, C. M., \& Cabrera, A. F. (2014). Making the mark: are grades and deep learning related? Research in Higher Education, 55(5), 494-507.

[8] Carini, R. M., Kuh, G. D., \& Klein, S. P. (2006). Student engagement and student learning: Testing the linkages. Research in Higher Education, 47(1), 1-32.

[9] CHEN, Y., YAN, D.-y., \& MING, D.-f. (2009). Practice and Thoughts on the Implementation of the National College Students Innovation Experiment Program [J]. Journal of Beijing Institute of Technology (Social Sciences Edition), 2, 026 .

[10] Choi, B. K., \& Rhee, B. S. (2014). The influences of student engagement, institutional mission, and cooperative learning climate on the generic competency development of Korean undergraduate students. Higher Education, 67(1), 1-18.

[11] Duff, A., Boyle, E., Dunleavy, K., \& Ferguson, J. (2004). The relationship between personality, approach to learning and academic performance. Personality and individual differences, 36(8), 1907-1920.

[12] Duque, L. C., \& Weeks, J. R. (2010). Towards a model and methodology for assessing student learning outcomes and satisfaction. Quality assurance in education, 18(2), 84-105.

[13] Guay, F., Ratelle, C. F., \& Chanal, J. (2008). Optimal learning in optimal contexts: The role of self-determination in education. Canadian Psychology/Psychologie canadienne, 49(3), 233. 
[14] Hair, J. F., Black, W. C., Babin, B. J., Anderson, R. E., \& Tatham, R. L. (2006). Multivariate data analysis (Vol. 6): Pearson Prentice Hall Upper Saddle River, NJ.

[15] Hart, G., Bowden, J., \& Watters, J. (1999). Graduate Capabilities: a Framework for Assessing Course Quality 1. Higher education in Europe, 24(2), 301-308.

[16] Hennemann, S., \& Liefner, I. (2010). Employability of German geography graduates: The mismatch between knowledge acquired and competences required. Journal of Geography in Higher Education, 34(2), 215-230.

[17] Hmelo-Silver, C. E., Duncan, R. G., \& Chinn, C. A. (2007). Scaffolding and achievement in problem-based and inquiry learning: A response to Kirschner, Sweller, and Clark (2006). Educational Psychologist, 42(2), 99-107.

[18] Kellermann, P. (2007). Acquired competences and job requirements Careers of university graduates (pp. 115-130): Springer.

[19] Kyriakides, L., Christoforou, C., \& Charalambous, C. Y (2013). What matters for student learning outcomes: A meta-analysis of studies exploring factors of effective teaching. Teaching and teacher education, 36, 143-152.

[20] Laird, T. F. N., Shoup, R., Kuh, G. D., \& Schwarz, M. J. (2008). The effects of discipline on deep approaches to student learning and college outcomes. Research in Higher Education, $49(6), 469-494$.

[21] Lave, J., \& Wenger, E. (1991). Situated learning: Legitimate peripheral participation: Cambridge university press.

[22] Marginson, S. (2011). Higher education in East Asia and Singapore: Rise of the Confucian model. Higher Education, 61(5), 587-611.

[23] Marton, F., \& Säljö, R. (1976). On qualitative differences in learning: I-Outcome and process. British journal of educational psychology, 46(1), 4-11.

[24] Nespor, J. (1987). The role of beliefs in the practice of teaching. Journal of curriculum studies, 19(4), 317-328.

[25] Nygaard, C., Højlt, T., \& Hermansen, M. (2008). Learning-based curriculum development. Higher Education, 55(1), 33-50.

[26] Oleson, A., \& Hora, M. T. (2014). Teaching the way they were taught? Revisiting the sources of teaching knowledge and the role of prior experience in shaping faculty teaching practices. Higher Education, 68(1), 29-45.

[27] Pace, C. R. (1984). Measuring the Quality of College Student Experiences. An Account of the Development and Use of the College Student Experiences Questionnaire.

[28] Pike, G. R., Kuh, G. D., McCormick, A. C., Ethington, C. A., \& Smart, J. C. (2011). If and when money matters: The relationships among educational expenditures, student engagement and students' learning outcomes. Research in Higher Education, 52(1), 81-106.
[29] Pike, G. R., Smart, J. C., \& Ethington, C. A. (2012). The mediating effects of student engagement on the relationships between academic disciplines and learning outcomes: An extension of Holland's theory. Research in Higher Education, 53(5), 550-575.

[30] Pike, G. R., Smart, J. C., Kuh, G. D., \& Hayek, J. C. (2006). Educational expenditures and student engagement: When does money matter? Research in Higher Education, 47(7), 847-872.

[31] Qureshi, I., \& Compeau, D. (2009). Assessing between-group differences in information systems research: A comparison of covariance-and component-based SEM. MIS quarterly, 197-214.

[32] Ramsden, P. (2003). Learning to teach in higher education: Routledge.

[33] Schaufeli, W., \& Salanova, M. (2007). Work engagement. Managing social and ethical issues in organizations, 135, 177.

[34] Schaufeli, W. B., Salanova, M., González-Romá, V., \& Bakker, A. B. (2002). The measurement of engagement and burnout: A two sample confirmatory factor analytic approach. Journal of Happiness studies, 3(1), 71-92.

[35] Shephard, K. (2008). Higher education for sustainability: seeking affective learning outcomes. International Journal of Sustainability in Higher Education, 9(1), 87-98.

[36] Shin, J. C., \& Harman, G. (2009). New challenges for higher education: Global and Asia-Pacific perspectives. Asia Pacific Education Review, 10(1), 1-13.

[37] Tagg, J. (2003). The learning paradigm college: Anker Publishing Company Bolton, MA.

[38] Taylor, B. J., Webber, K. L., \& Jacobs, G. J. (2013). Institutional Research in Light of Internationalization, Growth, and Competition. New directions for institutional research, 2013(157), 5-22.

[39] Vescio, V., Ross, D., \& Adams, A. (2008). A review of research on the impact of professional learning communities on teaching practice and student learning. Teaching and teacher education, 24(1), 80-91.

[40] Weerts, D. J. (2007). Toward an engagement model of institutional advancement at public colleges and universities. International Journal of Educational Advancement, 7(2), 79-103.

[41] Wong, D. K. P., \& Lam, D. O. B. (2007). Problem-based learning in social work: A study of student learning outcomes. Research on Social Work Practice, 17(1), 55-65.

[42] Zepke, N., \& Leach, L. (2010). Improving student engagement: Ten proposals for action. Active learning in higher education, 11(3), 167-177. 